\title{
Personification of a Cat Robot Design for Early Treatment of Children with Developmental Disorders
}

\author{
Keum-hi Mun \\ Semyung University, Industrial Design Department, Semyung-ro 65, Jecheon-si, \\ Chungbuk-do, R. O. Korea \\ khmun@semyung.ac.kr
}

\begin{abstract}
A study on an animal shaped robot that has an animal-assisted therapy effect on early treatment for children with developmental disorders and has ino dangerous elements of infection or allergy, like a real animal, has been started since the late 90s. A cat is selected as the object animal of the robot for early treatment of chitdren with developmental disorders, according to the result of their preference research. Formaking the cat Jobot more efficient on the therapeutic value, personification must be applied. Personification which reflects the image of an animal or a man on the shape of a robt, makes a man accept a robot as more familiar, and makes it easier to convey a chacacter of a robot to a man through the outward appearance or movements. Therefore, the personification method of a cat robot is researched through prior theses and literatures, Through the results of the study, basic emotions of the cat robot were selected 4 emotions: surprise, angersorrow, and happiness. To the design of the cat robot, standards are estished and applied to personification, such as outward appearance, facial expressions, emotional expressions and movements.
\end{abstract}

Keywords: Persopification, Cat Robor Design, Children with Developmental Disorders

\section{Introduction}

A study on an animal shaped robot that has an animal-assisted therapy effect on early treatment for children with developmental disorders, and has no dangerous elements of infection or allergy such as like a real animal, has been started in the late 90's. It is established that an animal shaped robot is effective in the treatment for children with developmentai disorders and has treatment efficiency. A cat is selected as an object animal of robot for an early treatment of children with developmental disorders according to the result of their preference research. For making the cat robot more efficient on the therapeutic value, personification must be applied. "Personification" is a design method which is applied not only on robots but also on various industrial products. The main purposes of using personification in industrial design are making a man accept a robot as more familiar, and making it easier to convey the character of a product through the outward appearance or movements to a man. According to a study of Kwak \& Kim (2009) it is researched that if the features of a robot are more like a friend, warm, and pleasant, the man is more sympathetic to the robot [1]. As a matter of 
fact, a facial expression of an animal is different from that of a man. But for a man to have sympathy with an animal robot and to give a favorable impression, it needs personification that makes imitation of facial expressions or actions of a man to some extent. Therefore this study will establish concept for applying to cat robot design for early treatment of children with developmental disorders. For applying personification to a cat robot, purpose, meaning, effect, and method of personification were researched through existing theses and literatures. The case study of existing personified product robots and facial expressions of real cats were researched to establish the basic direction of cat robot design.

\section{Theoretical Background}

\subsection{Personification}

Personification is one conception of Synectics. Direct Anabgy, Personal Analogy, Symbolic Analogy, Fantasy Analogy, etc., are examples /or syectics. Synectics, developed by W. Gorden, is a method to searching new one by combining things which appear to have no connection with each other. But personification could be found as a technique in our classical literature, so its origin appears not new. Personification, in robot design, means a method which throws aninage on the robot's shape, movement, sound, etc., by a human being. Personification is applied not only a field of robot products, but also several field of video, animation, the main purpose of it is that man accepts the object as more friehdly, and its character is more easily transferred through movement, sound, etc. Carl Disalvo suggests Structural, Character, Gestural, Aware as the standards of applying personification [2]. Lee \& Kim (2009) insisted that animal character and human character all múst be considered, because, when an animal is expressed by the shape of personffication, a non-verbal area (outward form, nonverbal action of man, habit, action, behavior of animal) is very important in animation for the creation of animal character [3]. Therefore when the cat robot is designed, as standards of personification, outward form which belongs to structural character and outward appearance, facia expression which belongs to character and non-verbal action, gestures which belongs to gestural character, animal's habit, actions, behavior, and sound would bé applied.

\subsection{Case study on personification of robot}

For a case study on personification of robots, robots are classified into humanoid type, animal type, and product type.

2.2.1 Humanoid type robot: Humanoid type robot is originally made to look like a man. Personification is the inevitable purpose, but has technical limitations and must pay attention not to fall into 'an uncanny valley'. 'Uncanny Valley' is presented by Doctor Masahiro Mory in 1970, Japan. It means as the external appearance or action of the robot is more like that of a man, the more a feeling of intimacy increases, however, when it looks like a man excessively, 
to the contrary it can give a feeling of disgust. Humanoid type robots for early treatment of children with developmental disorders are 'Kasper', 'Robota', etc. Personification of robot for early treatment of children with developmental disorders are 'making eye contact', 'copy body movements', 'various kinds of actions', and 'negative reactions', etc. Through the robot 'Caspar' this personification methods are analyzed [4].

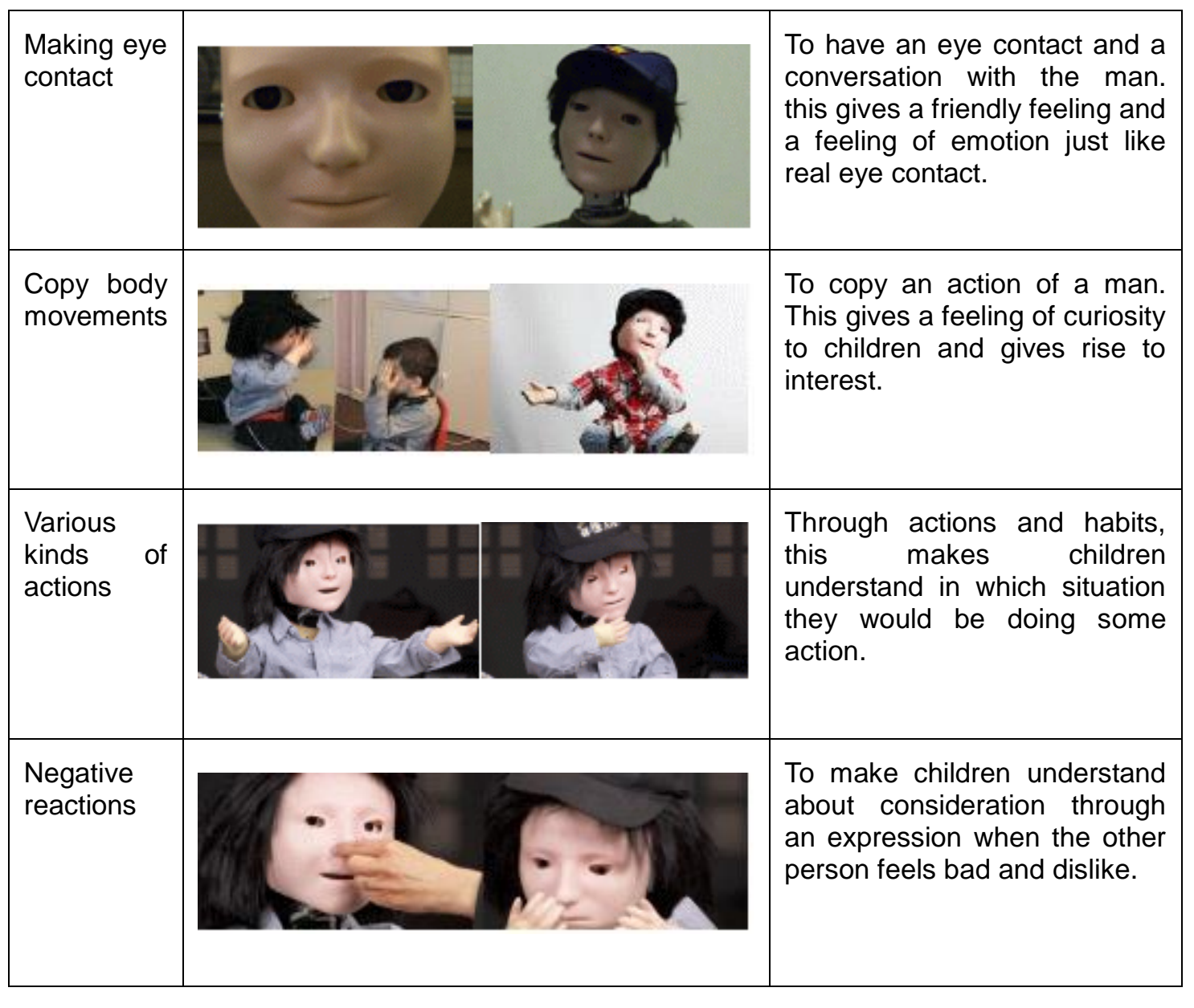

Figure 1. Personification of humanoid type robot 'Kaspar'

2.2.2 Animal type robot: Personification of animal robot is personified to increase a familiarity and awareness of function and character a human. Emotional animal robots are domestic Kobie' [5] of ETRI (Korean Electronics and Telecommunications Research Institute), entertainment pet dog robot 'Aibo' [6], a cure robot shaped seal pups 'Paro' [7] of AIST, made just like a space animal 'Furby' [8], etc. There are two ways of represent facial expression. The first is a way to make facial expression by moving muscles, and the second is to show emoticon or eye shape by the use of LCD. 


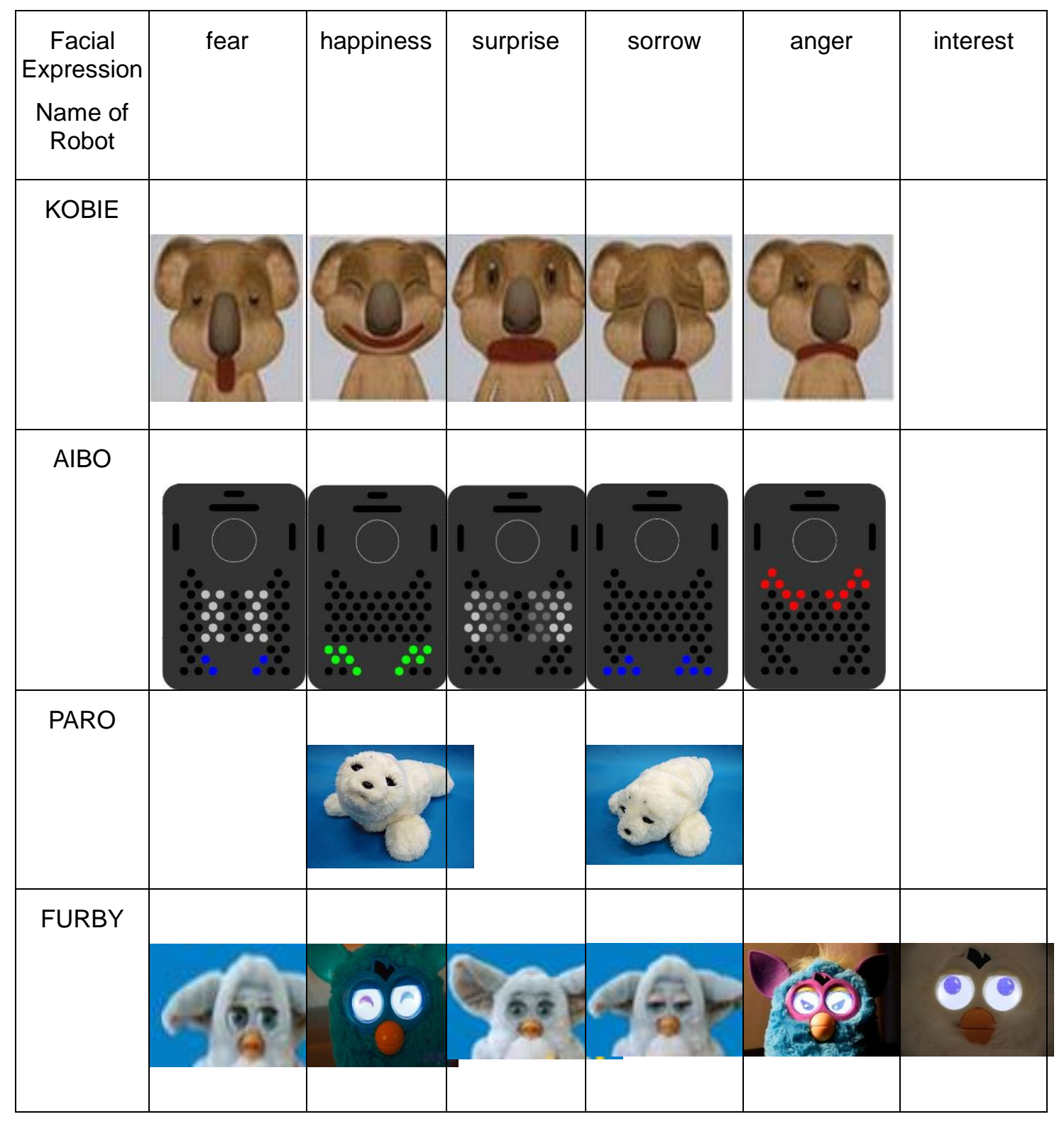

Figure 2. Facial expression of animal type robot for personification

2.2.3 Product type robot: Product Robots can do work, which men must do by themselves, with artificial intelligence, according to even previously preserved data. They are applied to personification for raising likeability, familiarity, and awareness with differences of degree. The category of product robots is very broad but the cases which have relation with this study are 'Engkey' [9] of KIST (Korea Institute of Science and Technology) and 'Keepon' [10] of Carnegie Mellon University. 


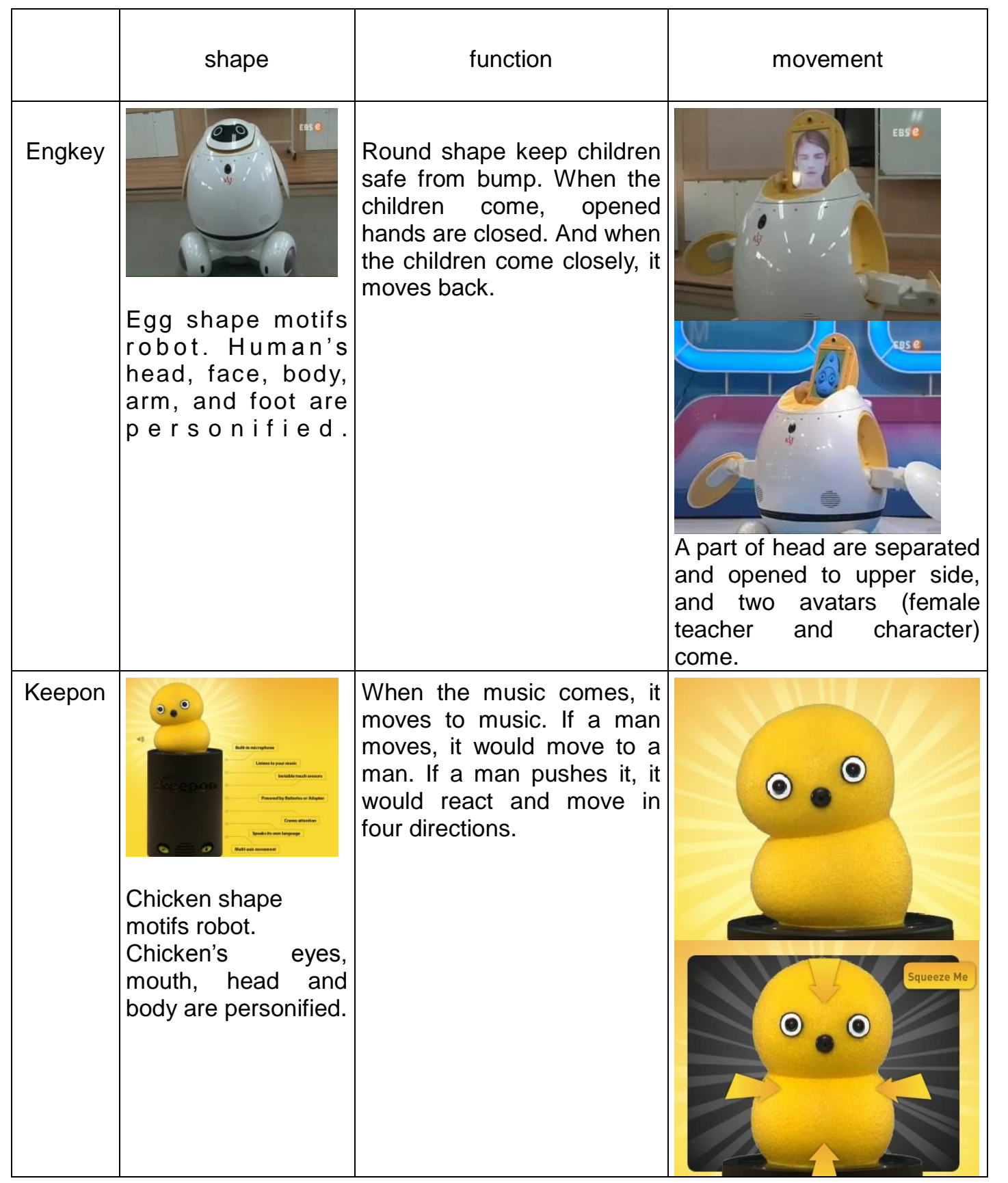

Figure 3. Shape and movement of product type robot for personification

\section{Applying Personification to a Cat Robot Design}

\subsection{Applying character to a cat robot design}

The outward appearance of cat robot must give a mild, warm, gentle, and friendly feeling to prevent the children with developmental disorders from having an aversion to the robot. The whole shape must look like a cat but should be personified by a human's form. Because this involves early treatment of children with developmental disorders, it is absolutely 
necessary that the robot be able to perform the functions of hug, eye contact, copy body movements, and appropriate reaction to inappropriate behavior. The size of a cat robot must enable the robot to be able to hug a 5-7 year old small child is made by $50 \mathrm{~cm}$ tall.

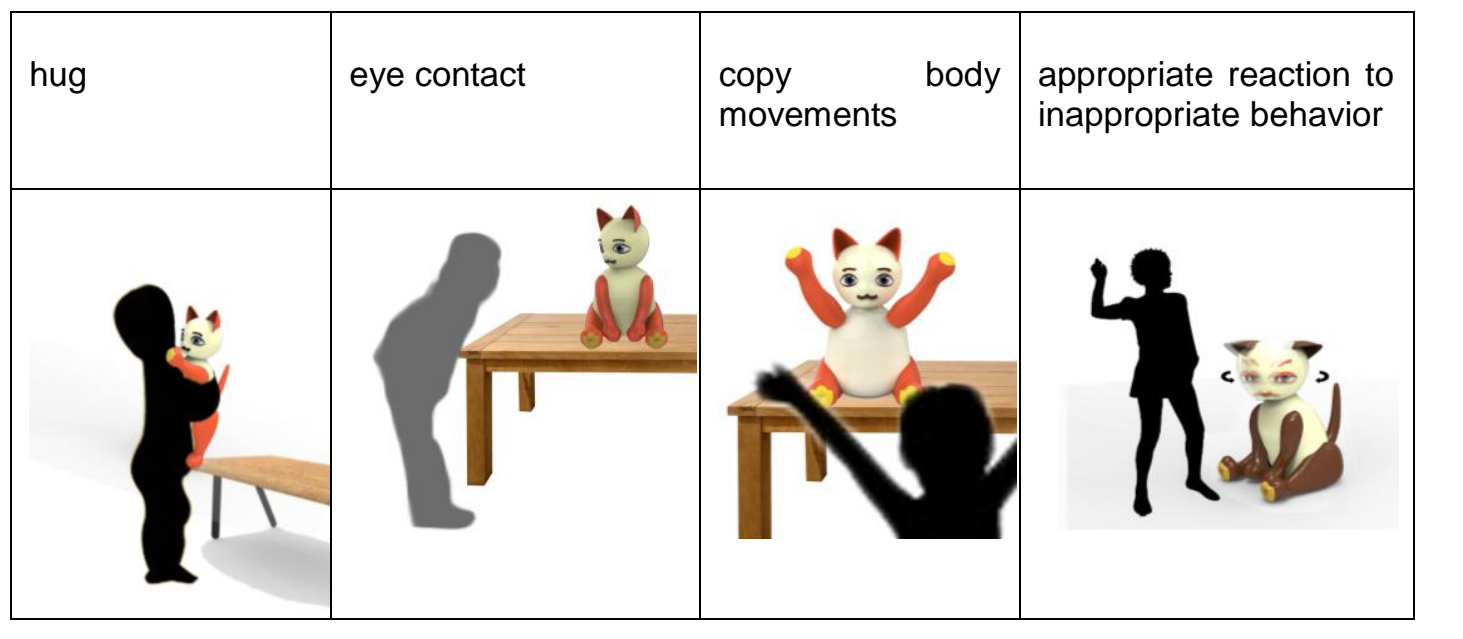

Figure 4. Shape and movement of a cat robot design for personification

\subsection{Applying emotional expression to a cat robot désign}

Lee (2003) analyzed existing studies of Cdevelopmen robot's reactive motion design management tool, after picking the common emotions fear, anger, sorrow, happiness, disgust from the existing classification of common emotions [M]. In this study, surprise, angry, sorrow and happiness are selected as common emotions. Simple, minimal expressions are more effective than too much emotional expression.

\subsection{Applying facial expression to a cat robot design}

The facial expression 61 r real cat is different from a man. Only a man who feeds a cat can understand the facial expression of a eat, because they will sympathize with the cat. They understand the cat because they always observe the cat, others cannot understand with ease. Facial expressions of a cat are satisfaction, paying attention, uncertain situations, scared, excited condition, curious anger, great anger, difference of appearance [12].

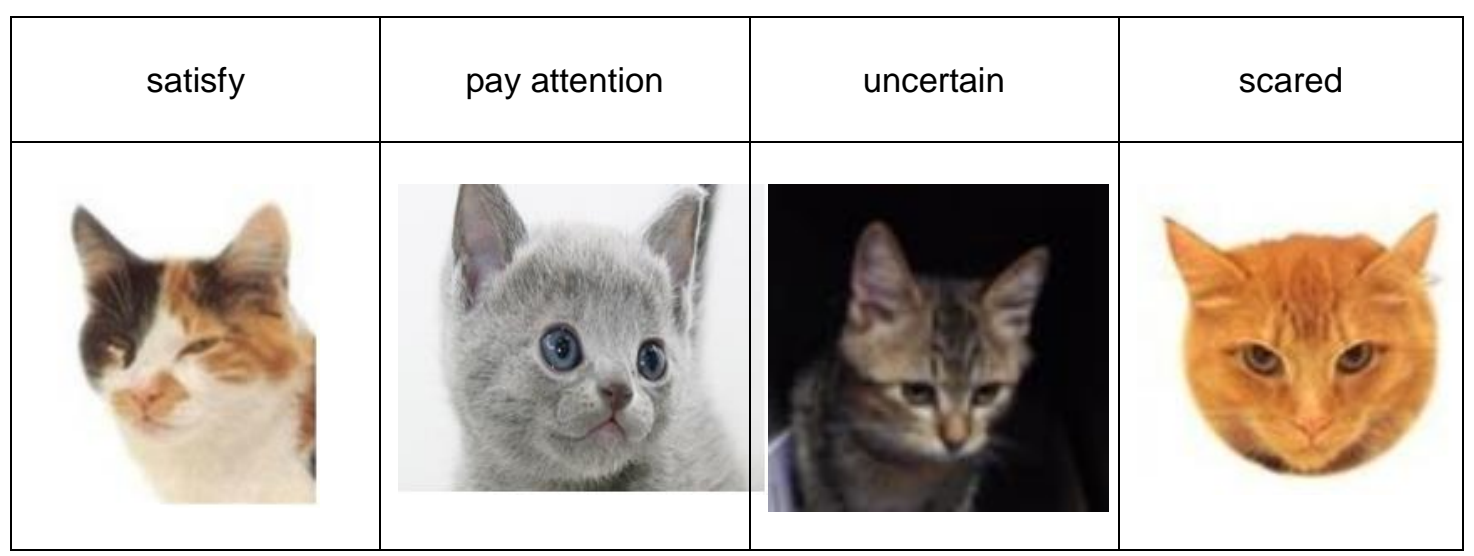




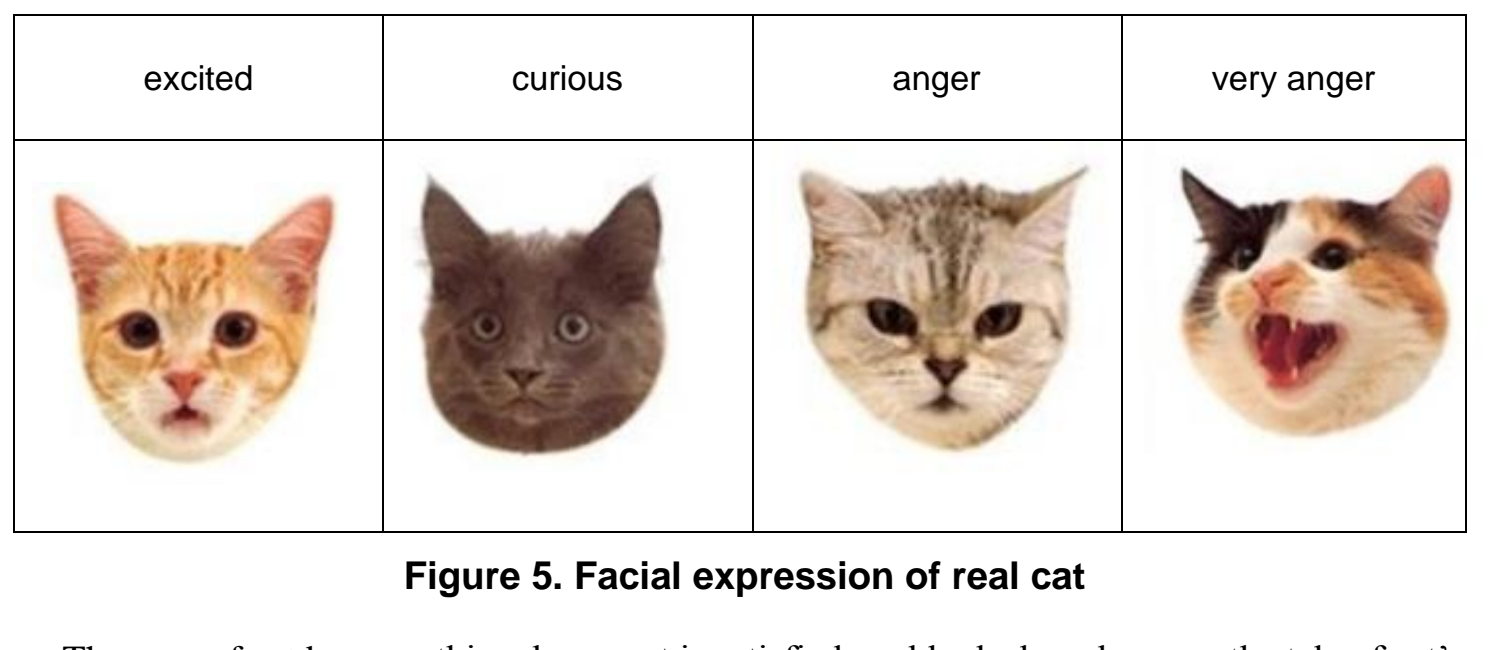

The eyes of cat become thin when a cat is satisfied, and look sharp because the tale of cat's eye is a slanted line. On the other hand, the shape of man's eyes is thin but the upper part is round. Therefore, it can be confirmed that on the case study of animal robots like Kobie and Furby, their eyes are personified to the shape of man's e es. For the expression of satisfaction, if the eyes are expressed like a real cat, a man who does not know about the emotional expressions of a cat could misunderstand that a cat 15 angry. Because as in the above case study, when angry Furby and Eibo's eyes are the same as satisfied cat's eyes. So facial expression of a cat robot must look like the personified man's facial expression, rather than look like the facial expression of a real cat.

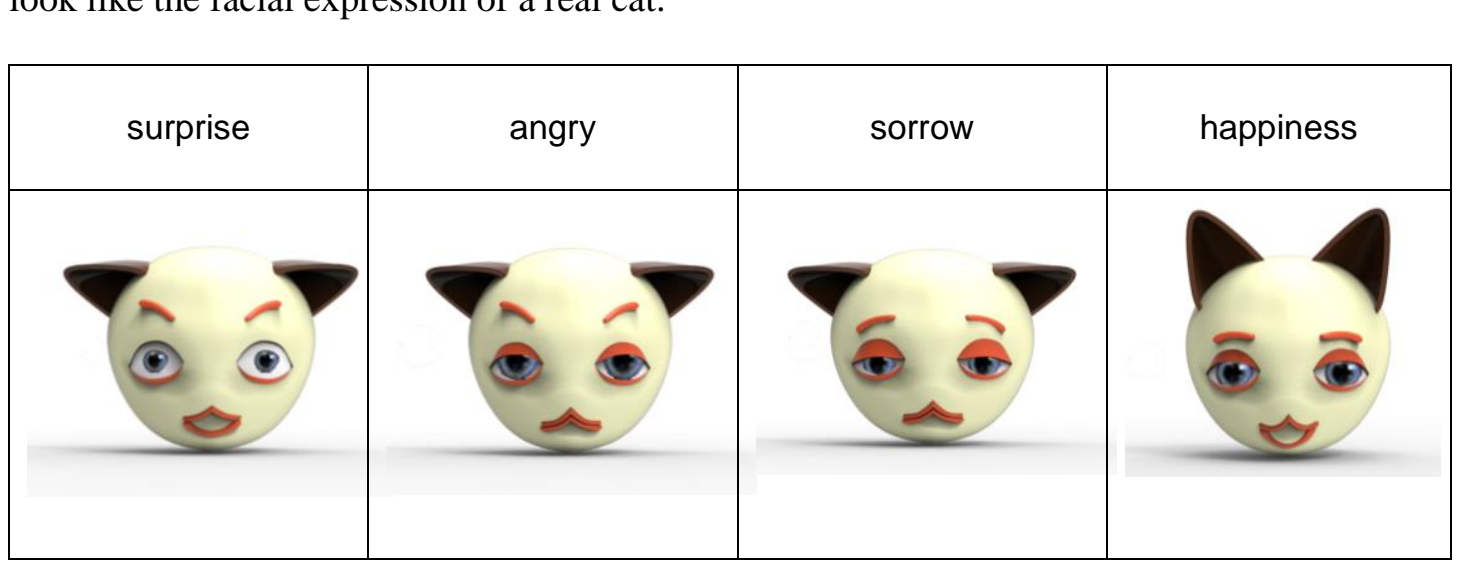

Figure 6. Personified facial expression of a cat robot design

\subsection{Applying movements and gesture to a cat robot design}

If a car robot is expressed as a personified shape, animal character and human character are all necessary concerns. Because when animal character is established, it is very important that not only outward form, but also the nonverbal communication areas such as nonverbal action of man, habits, action of animal, etc., be considered. Morris (2004) observes the movements and gestures of man and analyzes the behavior of human to movements and gesture. That is, he classified as native movement that which is not needed to be learned that which is learned through exercised movement. He defined gesture as only doing by a man and movement that sends a message to a watching man [13]. In human nonverbal communication commands more than $70 \%$ of human communication [14]. In animation, facial items of shaped element animal personification character is in order of eyes, eyebrows, and mouth. 
Eyes are highest ranking of personification frequency. Eears and nose, which have no movement, are never personified. When animal character is closer to human character, the more analyzed two foots walk, produce a voice of human, gesture, facial expression, and gaze [15]. Therefore when applying personification to a cat robot design, it must be designed with importance in order of eyes, eyebrows, and mouth.

\section{Conclusion}

This thesis is a study on applying personification to a cat robot design for early treatment of children with developmental disorders. At first studied on a personification, and classified case study object to personified robot as humanoid type, animal type, and product type. As a result of the case study, it must be applied to personification of a cat robot's 'making eye contact', 'copying body movements', 'appropriate reaction to inappropriate behavior' and 'hug'. Applications of character to personification of a cat robot are outward appearance, facial expression, movement, communication ability, and contents. The whole shape must look like a cat but it will personified by human's form. Applying emotional expressions are not to be excessive. Expressions selected are surprise, anger sorrow and happiness. Facial expression of a cat robot design must look like the facial expression of a man, because the facial expressions of real cat can lead to misunderstanding. Applying movements and gesture to a cat robot design must be personified with the concern all of human character and animal character. A study from now on, based on this study would progress to improve design, apply to robot development, and, after it needs verification, to the effect for early treatment of children with developmental disorders.

\section{Acknowledgements}

This paper was supported by the Semyung University Research Grant of 2013.

\section{References}

[1] S. S. Kwak and E. -h. Kim, "Design of the Emotional Robot for Human Empathy", Journal of Korean Society of Design Science, rol. 22, no. 5, (2009).

[2] C. Disalvo, F. Gemperle and J. Folizzi, "Imitating the Human Form: Four Kinds of Anthropomorphic Form", Futureground 04 Proc., (2004).

[3] Y. -s. Lee and J. -h. Kim, "A Study on the Step of Anthropomorphizing Animal Characters in Animations", Journal of Korea Multimedia Society, vol. 12, no. 11, (2009), pp. 1662.

[4] University of Hertfordshine, http://kaspar.herts.ac.uk/kaspar/kaspar-the-robot.htm.

[5] Tagstory, http://www.tagstory.com/video/100151689.

[6] You Tube KR, http://youtu.be/212P8Uz0LkA.

[7] Seal Type Mental Commit Robot PARO, http://www.paro.jp/english/function.html.

[8] You Tube KR, http://youtu.be/IAZ8QG8uz9I.

[9] EBS English, talk $\mathrm{n}$ issue $102^{\text {nd }}, \mathbf{( 2 0 1 1 )}$ February 25.

[10] My Keepon http://www.mykeepon.com.

[11] D. -k. Lee. "A Study on the Entertainment Robot Behavioral Structure and Reactive Motion Design", KAIST master's thesis, (2003), pp. 51.

[12] Puppy Korea \& Pet Korea, http://blog.naver.com/PostView.nhn?blogId=gkqwjddur1\&logNo=110150788422.

[13] D. Morris, "People Watching”, Gga Chi Ggul Bang (in Korea), (2004).

[14] Berko, Communication: A Social and Career Focus: Korean Culture Co. (in Korea), (2003).

[15] Y. -s. Lee and J. -h. Kim, "A Study on the Step of Anthropomorphizing Animal Characters in Animations", Journal of Korea Multimedia Society, vol. 12, no. 11, (2009), pp. 1666-1667. 


\section{Author}

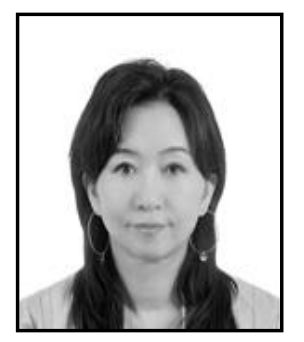

\section{Author's Name : Keum Hi Mun}

Author's profile : 1998-2014 Prof. of Semyung University

1993-1998 Prof. of Seoul Politechnics College

1987-1992 Designer of Ssangyong Motros Co.

2007-2010 Complete Doctoral Course of Western Phylosophy in Chungbuk University

1994-1996 Master of Industrial Dsign in Hongik ${ }^{\bullet}$ University

1975-1979 Bachelor of Industrial Design in Seoul National Uni yersity

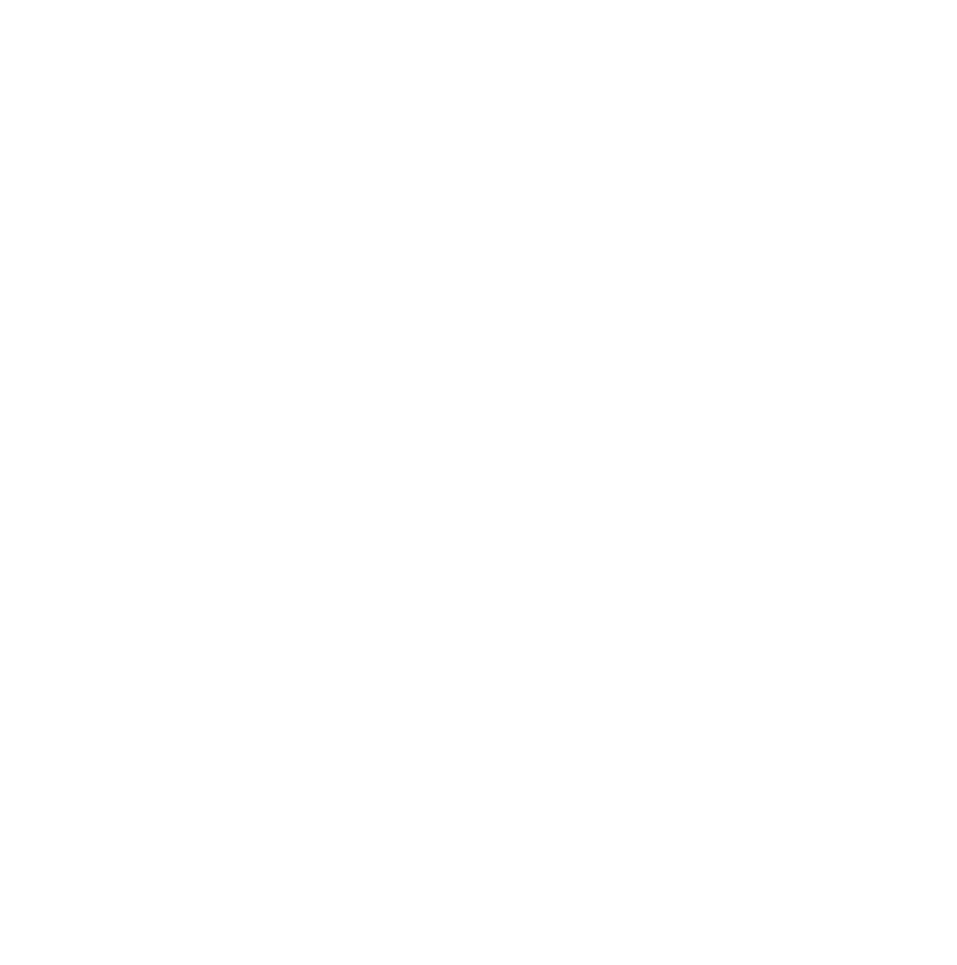


International Journal of Control and Automation

Vol.7, No.1 (2014)

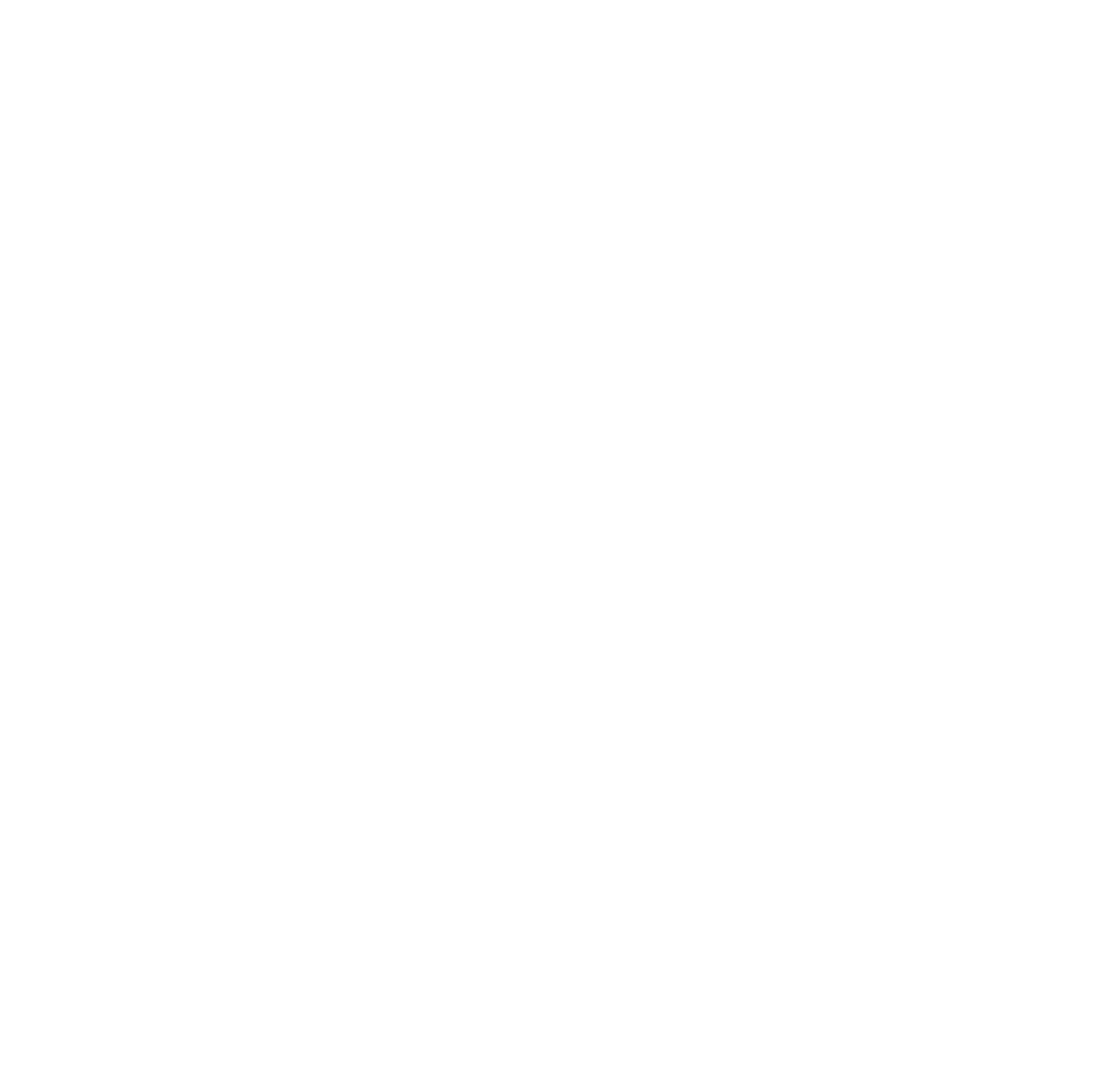

